\title{
Gorontalo
}

Journal of Government and Political Studies

Volume 3 - NO. 2 - Oktober 2020

P-ISSN: 2614-2120 E-ISSN: 2614-2104

\section{Komitmen Politik: Penegakan hukum \& Keberlanjutan Usaha Pemerintah Kota Tasikmalaya dalam Upaya Menurunkan Angka Stunting}

\author{
Della Trijuliana \\ Mochamad Faizal Rizki \\ Gili Argenti \\ Program Studi Ilmu Pemerintahan, Fakultas Ilmu Sosial dan Ilmu Politik \\ Universitas Singaperbangsa Karawang \\ Jalan HS. Ronggo Waluyo, Puseurjaya, Kab. Karawang \\ dellatrijuliana.dt@gmail.com \\ mochamad.faizal@fisip.unsika.ac.id \\ gili.argenti@fisip.unsika.ac.id
}

Received: 30th August 2020;

Accepted: 10th September 2020

\begin{abstract}
Stunted children are categorized as a problem in chronic nutrition which is motivated by many factors such as socioeconomic conditions, nutrition of pregnant women, morbidity in infants and malnutrition intake in infants and pregnant women. This research is motivated by the problem of stunting in the Tasikmalaya City which has a good stunting journey with the achievement of the prevalence of stunting falling in four years from 13,881 in 2016 to 5,986 children in 2019. Behind its success, it is possible that there was a good political commitment. This research was conducted with the aim of knowing how the Political Commitment of the City Government of Tasikmalaya in reducing the prevalence of stunting, which is highlighted in the commitment here is the aspect of law enforcement and business sustainability. The method used is descriptive research and data collection techniques with literature study and field studies, the data sources used are primary and secondary. The informants in this study consisted of 3 agencies and 5 public with certain criteria. Data analysis was performed data reduction, data presentation, and drawing conclusions. The results of this study indicate that the success of a policy is judged based on its political commitment. In policies related to stunting in Tasikmalaya City, it is already good, but in its implementation there are still several obstacles including in the dimension of law enforcement and business sustainability.
\end{abstract}

Keywords: law enforcement; business sustainability; stunting

\begin{abstract}
ABSTRAK
Anak stunting dikategorikan sebagai permasalahan gizi kronik yang dilatarbelakangi oleh banyak faktor contohnya kondisi sosial ekonomi, gizi ibu hamil, kesakitan pada bayi serta asupan gizi kurang pada bayi maupun ibu hamil. Penelitian ini diangkat karena permasalahan stunting di Kota Tasikmalaya yang memiliki perjalanan stunting baik dengan pencapaian prevalensi stunting turun dalam waktu empat tahun dari 13.881 di tahun 2016 menjadi 5.986 anak di tahun 2019. Dibalik kesuksesannya maka memungkinkan terdapat komitmen politik yang baik. Penelitian ini dilakukan dengan
\end{abstract}


tujuan untuk mengetahui bagaimana Komitmen Politik Pemerintah Kota Tasikmalaya dalam menurunkan prevalensi stunting, yang disorot dalam komitmen di sini adalah aspek penegakan hukum dan keberlanjutan usaha. Metode yang digunakan adalah penelitian deskriptif dengan teknik pengumpulan data studi pustaka dan studi lapangan, sumber data yang digunakan adalah primer dan sekunder. Informan pada penelitian ini terdiri dari 3 instansi dan 5 masyarakat dengan kriteria tertentu. Analisis data dilakukan reduksi data, penyajian data, dan penarikan kesimpulan. Hasil dari penelitian ini menunjukan bahwa berhasilnya suatu kebijakan dinilai berdasarkan komitmen politiknya. Dalam kebijakan terkait stunting di Kota Tasikmalaya memang sudah baik namun dalam pelaksanaanya masih terdapat beberapa hambatan termasuk dalam dimensi penegakan hukum dan keberlanjutan usaha.

Kata Kunci: penegakan hukum; keberlanjutan usaha; stunting

\section{PENDAHULUAN}

Arah Pembangunan Milenium atau Millenium Development Goals (MDGs) di dalamnya terdapat perbaikan multidimensi menjadi bagian dari aksi pembangunan secara internasional dimaklumatkan oleh Konferensi Tingkat Tinggi Milenium dari 189 negara anggota Perserikatan Bangsa Bangsa (PBB) bertempat di New York, September Tahun 2000. Dalam MDGs terdapat komitmen dari seluruh negara yang hadir untuk mengintegrasikan MDGs dalam menyelesaikan rumor yang beredar di khalayak umum terkait pemenuhan human rights and freedom, peace, security and development. Pelaksanaan MDGs harus diimplementasikan oleh negara-negara berkembang pun didukung oleh negara-negara maju untuk mencapai keberhasilan dari setiap tujuan dan target di dalamnya. Tujuan dalam MDGs ini ada 8 point agar bisa dicapai di tahun 2015 dengan implementasinya sudah dilakukan pada September Tahun 2000, 8 tujuan termaktub diantaranya 1) mengatasi kemiskinan dan kelaparan, 2) memperoleh pendidikan dasar bagi seluruh masyarakat, 3) mendorong kesetaraan gender dan pemberdayaan perempuan, 4) menekan angka kematian anak, 5) meningkatkan kesehatan ibu, 6) melawan HIV/AIDS, malaria serta penyakit menular lainnya, 7) memastikan kelestarian lingkungan hidup, dan 8) mengembangkan kemitraan global untuk pembangunan (Wahyuningsih, 2018: 393). Dalam capaiannya MDGs menghasilkan gerakan anti-kemiskinan paling sukses dalam sejarah (Liverman, 2018: 169-170).

Untuk melanjutkan MDGs yang sudah berakhir pada 2015 lalu maka dilakukan perluasan sebuah konsep pembangunan pasca 2015 yaitu Sustainable Development Goals (SDGs) atau Tujuan PembangunanB erkelanjutan. Menurut Akhir (dalam Wahyuningsih, 2018: 391) konsep SDGs merupakan sebuah alat kerangka pembangunan baru untuk mengatasi seluruh perubahan yang terjadi pasca MDGs 2015 yaitu isu deflasi sumber daya alam, kerusakan lingkungan, perubahan iklim semakin kritis, perlindungan sosial, food and energy security, dan pembangunan yang berpihak pada masyarakat miskin dengan sasarannya yang lebih universal dibandingkan dengan MDGs (Liverman, 2018: 177). SDGs merupakan kebijakan global digagaskan oleh Perserikatan Bangsa-Bangsa (PBB) yang diterapkan secara lokal guna mengakhiri kemiskinan ekstrim agar terwujudnya pembangunan berkelanjutan, maka dari itu program di dalamnya bertujuan untuk mengentaskan kemiskinan. Dalam SDGs tercantum 17 tujuan dan 169 target, tujuan tersebut bersifat luas dengan melibatkan negara maju dan berkembang, dikatakan SDGs ini memperkuat konvergensi agenda pembangunan internasional termasuk di 
Indonesia SDGs sudah menjadi prioritas pembangunan pun dalam aksinya telah searah dengan Rencana Pembangunan Jangka Menegah Nasional (RPJMN) 2015-2019 di tingkat nasional dan terstruktur dalam bentuk program, indikator dan indikasi dukungan pendanaan. Kerangka SDGs dirancang serta diuji dengan baik secara konseptual dan metodologi agar mampu berfungsi dengan handal, jika tidak maka hasil capaian SDGs akan bersifat ambigu (Rassanjani, (2018: 45), Janoušková et al., (2018: 2)). Dalam hal ini maka pemerintah perlu bersinergi bersama menyusun rangkaian perencanaan kebijakan di tingkat nasional serta tingkat daerah, selain pemerintah ada pun partisipasi luas dari beberapa kelompok masyarakat sipil dalam proses yang transparan (Sarabhai, 2015: 121).

Tujuan SDGs yang pertama adalah mengakhiri kemiskinan, tujuan yang kedua yaitu mengakhiri kelaparan, mencapai ketahanan pangan dan nutrisi yang baik dan mendukung pertanian berkelanjutan lalu di tujuan ke tiga menguatkan kehidupan yang sehat menjunjung kesejahteraan bagi seluruh usia. Ketiga tujuan tersebut memiliki keterkaitan satu sama lain apabila salah satunya tidak terwujudkan maka akan berdampak pada suatu persoalan. Seperti halnya kemiskinan di Indonesia masih menjadi momok yang menakutkan karena mampu menghambat pembangunan nasional. Berdasarkan penelitian Ishartono (2016: 160) pemerintah sejak tahun 1995 sudah melakukan upaya untuk mengatasi kemiskinan dengan ditetapkannya Inpres Desa Tertinggal lalu disusul Peraturan Presiden Nomor 15 Tahun 2010 tentang Percepatan Penanggulangan Kemiskinan sekaligus yang melatarbelakangi terbentuknya Tim Nasional Percepatan Penanggulangan Kemiskinan (TNP2K) sejak itu diketuai langsung oleh Wakil Presiden. Hingga saat ini masalah kemiskinan masih menjadi permasalahan yang diprioritaskan dan turut serta ada dalam tujuan SDGs yang pertama. Maka mampu kita nilai bahwa kemiskinan masih menjadi permasalahan yang sulit untuk diatasi dan dianggap sebagai masalah serius (Ishartono, 2016).

Permasalahan kemiskinan ini bisa berpengaruh pada berbagai aspek kehidupan, seperti status kesehatan dan ketahanan pangan. Jika seseorang memiliki ekonomi kurang akan sulit baginya mendapatkan pelayanan kesehatan yang baik dan status gizi baik. Jika kebutuhan gizi masyarakat tidak terpenuhi bisa mengakibatakan permasalahan gizi yang mana masalah gizi ini mampu menghambat jalannya pembangunan nasional hasilnya pun akan berakhir pada kemiskinan lagi. Permasalahan gizi menjadi salah satu permasalahan yang diprioritaskan dalam pembangunan nasional karena masalah gizi rentan kaitannya dengan balita. Menurut Handayani (Putri et al., 2015: 255) anak berusia di bawah lima tahun dinyatakan sebagai generasi penyambung bagi bangsa yang dituntut untuk memiliki sumber daya manusia yang berkualitas untuk masa depan. Pada usia ini dikatakan sebagai "usia emas" dalam membentuk sumber daya manusia yang bermutu maupun dalam membentuk fisik pun kecerdasan otak. Dalam aksinya tentu harus mendapat support pemberian gizi agar bisa menyandang kondisi gizi baik karena status gizi ini memiliki kedudukan untuk memastikan sukses tidaknya peningkatan sumber daya manusia.

Salah satu permasalahan gizi yang dinilai sulit untuk ditangani adalah stunting. Kementerian Perencanaan Pembangunan Nasional/Badan Perencanaan Pembangunan Nasional mengemukakan bahwa anak stunting memiliki 
kegagalan dalam pertumbuhan akibat kurang asupan gizi kronis di 1.000 Hari Pertama Kehidupan (HPK), hambatan dalam pertumbuhan fisik maupun otak mengakibatkan anak stunting sulit mendapat pekerjaan karena di masa mendatang mereka rentan terhadap penyakit kronis (Kementerian PPN/ Bappenas, 2018: iii). Stunting bisa disebabkan oleh adanya kemiskinan karena masyarakat kurang mampu membeli kebutuhan gizi yang seimbang sehingga masyarakat tidak mendapatkan asupan gizi yang lengkap, selain disebabkan oleh kemiskinan stunting juga bisa mengakibatkan kemiskinan di masa mendatang jika sang balita sudah dewasa perkembanganya terhambat dan proporsi badanya yang kerdil akan sulit bersaing secara global, pada tingkat lokal pun anak stunting akan sulit mendapatkan pekerjaan karena tubuh yang tidak normal mengakibatkan sulit terjangkaunya perkembangan fisik dan kognitif yang optimal (Kementerian Kesehatan Republik Indonesia, 2018: 2).

Di Indonesia berdasarkan Riset Kesehatan Dasar (Riskesdas) angka stunting mencapai 30,8\% di tahun 2018. Lalu di tahun 2019 dari survei Status Gizi Balita Indonesia (SSGBI) angka stunting menjadi 27,67\% (dalam Litbang.kemkes.go.id, 2019). Batas prevalensi normal stunting menurut WHO adalah 20\% (World Health Organization, 2013 : 12), jika sudah melebihi dari $20 \%$ seperti angka stunting di Indonesia maka sudah diwajibkan bagi pemerintah memberlakukan skala prioritas bagi penanggulangannya. Hingga saat ini Indonesia telah menerapkan program konvergensi stunting, pada aksinya di tahun 2021 akan difokuskan dan diprioritaskan pada seluruh wilayah Indonesia.

Permasalahan stunting membutuhkan komitmen langsung dari seorang pemimpin, sebagai seorang yang memimpin berjalannya proses pembangunan maka diharuskan seorang pemimpin itu membuat rancangan strategis untuk menanggulangi stunting khususnya di lokasi yang memiliki angka stunting tinggi. Namun dalam aksinya terdapat salah satu kota di wilayah Jawa Barat yang memiliki rekam jejak atau historis perjalanan stunting yang baik. Angka stunting di Indonesia sukar diturunkan namun di kota ini angka stunting berhasil diturunkan dalam waktu cepat. Kota tersebut adalah Kota Tasikmalaya.

Kota Tasikmalaya sejak tahun 2016 memiliki angka stunting tinggi yaitu 13.881 anak, namun di tahun 2019 turun menjadi 5.986 anak. Berdasarkan data lapangan dari Dinas Kesehatan Kota Tasikmalaya angka stunting di tahun 2019 sudah mencapai 10,95\%. Berikut disajikan penurunan angka stunting dari tahun 2016 sampai 2019 berdasarkan data Bulan Penimbangan Balita Dinas Kesehatan Kota Tasikmalaya:

Tabel 1. Jumlah Stunting di Kota Tasikmalaya

\begin{tabular}{cc}
\hline Tahun & Presentase \\
\hline 2016 & 13.881 \\
2017 & 6.263 \\
2018 & 5.290 \\
2019 & 5.986
\end{tabular}

(Sumber: Dinas Kesehatan Kota Tasikmalaya, 2019)

Berdasarkan tabel di atas angka stunting mengalami penurunan yang drastis dari tahun 2016 ke 2017. Sejak masa itu di tahun 2017 telah diangkat Walikota dan Wakil Walikota baru Kota Tasikmalaya periode 2017-2022 yaitu Drs. H. Budi Budiman dan Drs. H. Muhammad Yusuf. Namun Walikota 
Budi Budiman menjabat selama dua periode. Peneliti menganalisis jika pada periode keduanya beliau ini memiliki komitmen dalam menanggulangi penurunan angka stunting.

Kota Tasikmalaya mengalami penurunan yang signifikan dikarenakan pemerintahnya terus menggenjot berbagai program khususnya dalam program perbaikan gizi di masyarakat. Hal tersebut dibuktikan dalam RPJMD Kota Tasikmalaya 2017-2022 yang di dalamnya ada program bernama Program Tasik Sehat dilengkapi dengan program pendukung dari Dinas Kesehatan dengan target akhir di tahun 2020 ini prevalensi stunting mencapai angka 10\%, diantaranya program-program tersebut adalah Program Upaya Kesehatan Masyarakat, Program Promosi Kesehatan dan Pemberdayaan Masyarakat, Program Perbaikan Gizi Masyarakat, Program Peningkatan Pelayanan Kesehatan Keluarga, Program Inovasi Gemarak Bumil, serta kegiatan penyuluhan Isi Piringku, Program Inovasi Pemberian tablet FE (Zat Besi) pada remaja. Salah satu kegiatannya adalah pemberian biskuit pada ibu hamil maupun balita. Pemberian biskuit ini merupakan pemberian makanan tambahan bukan sebagai pengganti makanan sehari-hari. Selain biskuit bisa dengan variasi produk lain yang diberikan seperti susu coklat dengan biskuit susu, susu vanila dengan bihun, susu katuk dan biskuit coklat, susu coklat dan bihun, dan susu vanila dengan biskuit keju (Pastuty, R., KM, R., Herawati, 2018).

Kebijakan dan program-program tersebut merupakan turunan dari visi misi Wali Kota Tasikmalaya dan Janji-Janji Politik Kepala Daerah yang dituangkan ke dalam Program Pembangunan Daerah di RPJMD. Tujuan menurunkan prevalensi stunting ini diantaranya termaktub dalam misi yang ke dua yaitu "Mengurangi tingkat kemiskinan dan meningkatkan daya beli masyarakat" serta misi ke empat yaitu "Memenuhi kebutuhan pelayanan dasar masyarakat untuk meningkatkan kualitas sumber daya manusia". Pada misi ke dua dijelaskan bahwa pemerintah akan berupaya untuk terus menanggulangi kemiskinan, pendekatan dan merangkul masyarakat miskin, menekan kondisi perekonomian yang komprehensif serta continue melalui peningkatan perumbuhan dan pemerataan ekonomi, mengontrol inflasi dan menyurutkan kesenjangan, menekan pengangguran serta mendorong daya saing masyarakat pelaku usaha makro maupun mikro guna memperkuat sistem ekonomi kerakyatan berbasis potensi lokal, pengembangan sarana dan prasarana perekonomian, akses investasi dan lapangan kerja serta usaha, pengembangan akses untuk permodalan dan marketing sehingga daya beli juga daya saing masyarakat berkembang, tumbuh serta merebak. Pada misi ke empat menjabarkan bahwa untuk mengamalkan perkembangan mutu hidup sehat masyarakat maka Standar Pelayanan Minimal (SPM) harus terpenuhi melalui pendekatan keluarga sehat, bahagia dan sejahtera utamanya dalam masalah pendidikan, kesehatan, ketentraman, ketertiban umum dan perlindungan masyarakat sesuai dengan SPM. Dalam penjabaran misi tersebut mengartikan bahwa Walikota Budi Budiman berpegang teguh menjadikan masyarakat Kota Tasikmalaya hidup sehat didukung oleh ekonomi yang baik.

Berdasarkan penelitian dan data yang didapatkan di lapangan akibat terjadinya stunting di Kota Tasikmalaya disebabkan oleh Pendapatan Asli Daerah yang Rendah dan faktor kemiskinan. Menurut data Badan Pusat Statistik di tahun 2019 angka kemiskinan tertinggi di Jawa Barat adalah Kota Tasikmalaya. Faktor kemiskinan diartikan pendapatan masyarakat itu rendah. Status 
pendapatan akan berpengaruh pada kemampuan daya beli keluarga untuk memenuhi bahan pangan sehari-hari pun kebutuhan gizi agar seimbang sehingga jika kekurangan maka menyebabkan kurangnya gizi energi kronik pada ibu hamil (Rahayu \& Sagita, 2019 : 15). Selain terdapat masalah daya beli yang disebabkan oleh rendahnya daya beli, Kota Tasikmalaya juga menghadapi masalah lain, yaitu rendahnya tingkat pendidikan. BPS Kota Tasikmalaya melansir bahwa rata-rata masyarakat merupakan lulusan Sekolah Dasar atau sekitar 37,11\% berpendidikan SD (Badan Pusat Statistik Kota Tasikmalaya, 2020: 8). Hal ini merupakan faktor yang juga sangat berpengaruh pada pengetahuan akan pentingnya mendapatkan asupan gizi seimbang dan pola asuh anak yang baik.

Atas dasar permasalahan tersebut peneliti mencari dan mengkaji berbagai penelitian sebelumnya yang telah banyak mengulas mengenai fenomena stunting dalam berbagai perspektif, diantaranya penelitian berjudul "Hulu-Hilir Penanggulangan Stunting di Indonesia" oleh Rini dan Jeki (2019) yang mengemukakan bahwa di atas kaya akan level kebijakan namun di bawah miskin akan pengetahuan mengenai stunting, teori dalam penelitian ini menggunakan teori implementasi kebijakan dari Moris, SS (2008) (R. Saputri, 2019). Penelitian selanjutnya yaitu dari Weny Lestari, dkk yang berjudul "Stunting: Studi Konstruksi Sosial Masyarakat Perdesaan dan Perkotaan Terkait Gizi dan Pola Pengasuhan Balita di Kabupaten Jember" yang menggunakan teori konstruksi sosial dari Peter L. Berger dan Thomas Luckman dengan hasil penelitiannya disimpulkan bahwa kejadian stunting mempunyai letak permasalahan pada kondisi struktur sosial dan pemaknaan para implementor sehingga menyebabkan perspektif yang tidak ada solusinya bagi program peningkatan gizi balita (Lestari et al., 2018). Selanjutnya dari Dolf berjudul "Tanzania's Story of Change in Nutrition: Political Commitment, Innovation, and Shrinking Political Space" terdapat penurunan angka stunting selama masa pemerintahan baru di Tanzania dibawah pemerintahan Dr Jakaya Kikwete (2005-2015) angka stunting menjadi 44\% di tahun 2005 serta 34\% di masa kepemerintahan akhirnya yaitu 2015. Teori yang digunakan dalam penelitian ini menggunakan teori Komitmen Politik dari Brinkerhoff (2000), dan metode penelitian yang digunakan adalah kualitatif deskriptif (Dolf et al., 2020).

Teori yang digunakan pada penelitian ini memiliki persamaan teori penelitian Dolf yaitu teori Komitmen Politik dari Brinkerhoff (2000; 2010). Komitmen Politik muncul pada masa reformasi kebijakan, banyak penelitian yang mengungkapkan bahwa Komitmen Politik ini sulit dicari identifikasinya dan konsepnya seperti apa, lalu karakteristiknya bagaimana. Adanya struktur lembaga dikatakan sebagai respon praktis terhadap implementasi Komitmen Politik dan seringkali dikaitkan dengan proses birokrat dalam menjalankan sebuah kebijakan, Komitmen Politik pun diartikan sebagai wujud dari pengalokasian dana pemerintah untuk pencapaian hasil kebijakan, kapasitas dan tekanan publik lalu keterlibatan negara, aturan dan regulasi, serta tanggung jawab seseorang. Terlepas dari perspektif tersebut Brinkerhoff mengemukakan bahwa Komitmen Politik ini memiliki dua elemen yaitu niat (tidak bisa diukur) dan tindakan (mudah dilacak perwujudannya). Simpulan dari berbagai perspektif tersebut Brinkerhoff menarik makna sama dengan Political Will serta menyimpulkan bahwa ada lima dimensi untuk bisa mengukur Komitmen Politik yaitu Inisiatif Pemerintah, Prioritas, Mobilisasi Dukungan 
Politik, Penegakan Hukum dan Keberlanjutan Usaha. Namun yang paling penting di sini ada Penegakan Hukum dan Keberlanjutan Usaha karena pada saat itu Brinkerhoff mengkaji Komitmen Politik sebagai alat untuk menilai kegagalan pada anti korupsi. Maka jika penegakan hukum menjadi hal yang penting akan berpengaruh pada berlanjutnya sebuah produk kebijakan hingga melahirkan sesuatu yang bernilai positif (Boli et al., (2018), Chopra, (2015), Brinkerhoff, (2010), Fauzy, (2015)).

Penelitian ini bersifat best practice karena pada hasil implementasinya memiliki hasil yang baik. Maka atas dasar pertimbangan penelitian terdahulu dan temuan permasalahan di lapangan peneliti memutuskan untuk mengkaji mengenai "Komitmen Politik: Penegakan Hukum \& Keberlanjutan Usaha Pemerintah Kota Tasikmalaya dalam Upaya Menurunkan Angka Stunting". Maka peneliti ingin mengetahui apakah Kota Tasikmalaya memiliki komitmen politik yang baik jika angka stuntingnya turun dalam waktu cepat. Selama masa itu Kota Tasikmalaya dalam masa pemerintahan baru mengartikan bahwa adanya pembaharuan komitmen dari pasangan Walikota dan Wakil Walikota.

\section{METODE PENELITIAN}

Penelitian ini dilaksanakan dengan menerapkan metode kualitatif deskriptif. Teknik pengumpulan data dengan studi pustaka dan studi lapangan dilakukannya wawancara mendalam, dokumentasi dan observasi. Sumber data yang digunakan adalah sumber data primer yaitu pedoman wawancara dan rekaman hasil wawancara bersama Bagian Pemerintahan Sekda Kota Tasik, Sekretaris dan Pendamping Ketua Komisi IV DPRD, dan Ketua Kesehatan Keluarga dan Gizi Dinkes Kota Tasikmalaya lalu dari masyarakatnya terbagi menjadi tiga kriteria masyarakat pemilih pada pilkada 2017, ibu menyusui/ibu hamil serta anak remaja putri, dan sumber data sekunder yaitu studi kepustakaan berupa booklet stunting, pedoman intervensi gizi stunting, LPPD Dinas Kesehatan, Renstra dan Renja Dinkes Kota Tasikmalaya beserta RPJMD Kota Tasikmalaya.

Informan dalam penelitian ini adalah Kepala Bagian Pemerintahan Sekda Kota Tasikmalaya, Sekretaris dan Pendamping Ketua Komisi IV DPRD Kota Tasikmalaya, Ketua Seksi Kesehatan Keluarga dan Gizi, masyarakat dengan kriteria sebagai pemilih pada saat pilkada 2017, ibu hamil dan ibu menyusui serta remaja putri. Analisis data berupa reduksi data, penyajian data dan penarikan kesimpulan. Waktu penelitian dilaksanakan selama empat bulan dari Februari, Maret, Juli sampai Agustus di Kota Tasikmalaya.

\section{HASIL DAN PEMBAHASAN}

Komitmen Politik menurut Brinkerhoff (dalam Achmad et al., 2015 : 4) merupakan kemauan, keinginan atau langkah yang bertujuan untuk memperoleh seperangkat tujuan dilengkapi dengan upaya keberlanjutan atau secara ikhtiar. Komitmen politik dinilai sangat penting karena tercapainya suatu tujuan bangsa haruslah disertai dengan peran dari seorang politisi atau pemimpin dari bangsa itu sendiri. Tanpa adanya komitmen politik maka apa yang diharapkan dan direncanakan tidak akan tercapai dengan hasil yang baik.

Walikota Tasikmalaya memiliki inisiatif untuk menurunkan balita yang kekurangan gizi dengan tujuan menurunkan prevalensi stunting dan gizi buruk. Maka tindakan dari Walikota ini tertuang pada RPJMD Kota Tasikmalaya 2017- 
2022 bernama Program Tasik Sehat. Kebijakan tersebut kemudian diimplementasikan oleh aktor-aktor pemerintahan, masyarakat maupun swasta. Dalam aksinya program-program yang sudah berjalan sangat banyak dan memakan dana yang cukup besar yaitu Rp. 1.248.484.393,-, dikatakanlah permasalahan stunting sudah diprioritaskan di Kota Tasikmalaya jika program dan anggaranya sangat besar (Brinkerhoff, 2000;2010).

\subsection{Penegakan Hukum}

Pada dimensi Penegakan Hukum dimaksudkan adanya pemberian sanksi yang nyata, tegas dan seimbang sebagai penetapan akan komitmen pemerintah. Jika tidak ada hukum yang mengatur secara nyata, tegas dan seimbang maka kebijakan tersebut merupakan komitmen yang rendah. Artinya jika hukuman ini ringan maka tidak akan memberikan dampak jera serta dengan pasti akan terjadi lagi pelanggaran dengan peristiwa yang berbeda. Sanksi yang ditetapkan ini tentunya harus melalui proses perencanaan secara matang terlebih dahulu, apakah sanksi ini akan digunakan sebagai alat untuk kepatuhan terhadap kebijakan yang telah dibuat atau memberlakukan insentif bagi pelaksana dengan memberikan hasil positif berupa publikasi hasil yang telah terlaksana.

Penegakan Hukum pada Komitmen Politik Walikota Tasikmalaya ini dilihat dalam landasan hukum mulai dari tingkat nasional sampai daerah. Landasan hukum merupakan peraturan atau hukum dasar sebagai pedoman dalam melaksanakan kegiatan-kegiatan pemerintahan. Landasan hukum di tingkat nasional yang mendukung penurunan prevalensi stunting diantaranya UU Nomor 36 Tahun 2009 tentang Kesehatan, UU Nomor 18 Tahun 2012 tentang Pangan, UU Nomor 23 Tahun 2014 tentang Pemerintahan Daerah, Peraturan Presiden Nomor 42 Tahun 2013 tentang Gerakan Nasional Percepatan Perbaikan Gizi, Peraturan Presiden Nomor 83 Tahun 2017 tentang Kebijakan Strategis Pangan dan Gizi, Instruksi Presiden Nomor 1 tahun 2017 tentang Gerakan Masyarakat Hidup Sehat, Peraturan Menteri Perencanaan Pembangunan Nasional/Kepala Badan Perencanaan Pembangunan Nasional Nomor 1 Tahun 2018 tentang Rencana Aksi Pangan dan Gizi yang menetapkan RAN-PG, Pedoman Penyusunan RAD-PG, dan Pedoman Pemantauan dan Evaluasi RAN/RAD-PG, Surat Keputusan Menteri Koordinator Kesejahteraan Rakyat Nomor 11 Tahun 2014 tentang Tim Teknis Gerakan Nasional Percepatan Perbaikan Gizi, dan Surat Keputusan Deputi Bidang Sumber Daya Manusia Kementerian Perencanaan Pembangunan Nasional/Badan Perencanaan Pembangunan Nasional Nomor 37/D1.1/06/2014 tentang Kelompok Kerja Gerakan Nasional Percepatan Perbaikan Gizi. Kota Tasikmalaya belum memiliki Peraturan Daerah yang secara khusus mengatur permasalahan stunting namun dalam aksinya dasar hukum atau landasan hukum implementasi program-program perbaikan gizi di Kota Tasikmalaya mengacu pada RPJMD Kota Tasikmalaya 2017-2022, Renstra Dinas Kesehatan Kota Tasikmalaya tahun 2020, dan Rencana Kerja Dinas Kesehatan Kota Tasikmalaya 2020. Berkenaan dengan hal tersebut dikatakan pengaturan dalam Peraturan Daerah harus bisa mengatur urusan kewenangannya sesuai dengan karakteristik daerahnya dan tidak bertentangan dengan peraturan perundang-undangan yang lebih tinggi. Maka dapat ditarik sebuah makna terhadap sinkronisasai dan harmonisasi peraturan menjadi hal yang sangat penting (Nur, $2014: 160)$. 
Perihal pemberian sanksi tegas Pemerintah Kota Tasikmalaya sangat disayangkan tidak menetapkan sanksi spesifik untuk program pengendalian gizi masyarakat. Namun berdasarkan pernyataan Sekretaris Komisi IV DPRD Kota Tasikmalaya bahwa sanksi tegas akan ada jika pelanggaran berat terjadi maka proses sanksinya pun melalui aturan hukum dari Peraturan Pemerintahan Pusat. Namun pada fakta di lapangan bahwa program-program perbaikan gizi ini berjalan semestinya dan tidak mengalami hambatan serius seperti aksi suap atau korupsi dana stunting. Dalam prosesnya pun DPRD bersama OPD terkait melakukan evaluasi setiap bulannya apakah pelaksanaan program-program perbaikan gizi memiliki kegagalan serius atau berjalan sesuai yang diharapkan. Pemerintah Kota dinilai tidak memiliki kegagalan dalam menjalankan kebijakan perbaikan gizi, hal tersebut dibuktikan dengan data:

Tabel 2: Persentase Balita Stunting yang Mendapat Pelayanan Kesehatan Kota Tasikmalaya Tahun 2019

\begin{tabular}{|c|c|c|c|c|c|}
\hline No & Kecamatan & Puskesmas & $\begin{array}{c}\text { Jumlah balita } \\
\text { Stunting } \\
\text { ditemukan }\end{array}$ & $\begin{array}{l}\text { Jumlah balita } \\
\text { stunting yang } \\
\text { mendapat } \\
\text { pelayanan } \\
\text { kesehatan }\end{array}$ & Presentase (\%) \\
\hline \multirow[t]{3}{*}{1} & Kawalu & Kawalu & 508 & 508 & 100,00 \\
\hline & & Karanganyar & 548 & 548 & 100,00 \\
\hline & & Urug & 252 & 252 & 100,00 \\
\hline \multirow[t]{2}{*}{2} & Tamansari & Tamansari & 707 & 707 & 100,00 \\
\hline & & Sangkali & 59 & 59 & 100,00 \\
\hline 3 & Cibeureum & Cibeureum & 410 & 410 & 100,00 \\
\hline 4 & Purbaratu & Purbaratu & 219 & 219 & 100,00 \\
\hline \multirow[t]{2}{*}{5} & Tawang & Tawang & 130 & 130 & 100,00 \\
\hline & & Kahuripan & 465 & 465 & 100,00 \\
\hline \multirow[t]{2}{*}{6} & Cihideung & Cihideung & 513 & 513 & 100,00 \\
\hline & & Cilembang & 245 & 245 & 100,00 \\
\hline \multirow[t]{2}{*}{7} & Mangkubumi & Mangkubumi & 592 & 592 & 100,00 \\
\hline & & Sambongpari & 265 & 265 & 100,00 \\
\hline \multirow[t]{2}{*}{8} & Indihiang & Indihiang & 328 & 328 & 100,00 \\
\hline & & Parakanyasag & 100 & 100 & 100,00 \\
\hline \multirow[t]{3}{*}{9} & Bungursari & Bungursari & 192 & 192 & 100,00 \\
\hline & & Sukalaksana & 114 & 114 & 100,00 \\
\hline & & Bantar & 36 & 36 & 100,00 \\
\hline \multirow[t]{4}{*}{10} & Cipedes & Cipedes & 66 & 66 & 100,00 \\
\hline & & Panglayungan & 123 & 123 & 100,00 \\
\hline & & Cigeureung & 115 & 115 & 100,00 \\
\hline & \multicolumn{2}{|c|}{ Jumlah } & 5.986 & 5.986 & 100,00 \\
\hline
\end{tabular}

(Sumber: Dinas Kesehatan Kota Tasikmalaya, 2019)

Dari data di atas menunjukan bahwa 5.986 anak stunting di Kota Tasikmalaya sudah mendapatkan pelayanan kesehatan secara merata. Namun demikian Kota Tasikmalaya perlu mencapai target zero stunting agar Kota Tasikmalaya bersih dari angka stunting.

Selain tidak adanya sanksi yang ditetapkan, terdapat insentif yang menjadi indikator kuat dalam menentukan penegakan hukum. Aspek insentif adalah pemberian reward atau penghargaan bagi unit pelaksana. Berkenaan dengan hal tersebut, Pemerintah Kota Tasik tidak memberikan insentif apapun terhadap unit pelaksanannya terkecuali untuk DPRD dan Dinas Kesehatan yang memiliki ketentuan khusus memberikan penghargaan bagi implementor program jika program tersebut berhasil dan mencapai target. 
Penurunan dan pencapaian pemerataan pelayanan kesehatan menjadi hal yang lebih dan positif bagi Pemerintah Kota Tasikmalaya utamanya Dinas Kesehatan karena sebagai penanggung jawab utama untuk perbaikan gizi masyarakat. Hasil dari pencapaian tersebut maka DPRD mengadakan insentif bagi dinas-dinas yang ikut serta di dalam program perbaikan gizi berupa pemberian kemudahan untuk menarik anggaran dari DPRD. Sesuai dengan UU Nomor 22 Tahun 2003 tentang Susunan dan Kedudukan MPR/DPR/DPRD/DPD dan UU Nomor 32 Tahun 2004 tentang Pemerintahan Daerah menjelaskan bahwa fungsi DPRD salah satunya adalah fungsi anggaran.

Dinas Kesehatan dan Puskesmas pun mempunyai insentif tersendiri bernama Program Tenaga Kesehatan Teladan yang merupakan program dari Pemerintah Pusat. Pendamping ketua Komisi IV DPRD Kota Tasikmalaya berpendapat bahwa insentif dari Walikota Tasikmalaya itu sendiri memang tidak ditetapkan secara khusus karena menganggap bahwa pelaksanaan program untuk masyarakat merupakan suatu kewajiban bagi Aparatur Sipil Negara yang memang harus dilaksanakan namun Walikota selalu mengapresiasi hasil dan kerja keras dari OPD dalam melaksanakan kegiatan-kegiatan untuk mensuksesi kebijakan yang dikeluarkannya.

Maka hasil dari dimensi penegakan hukum ini diartikan bahwa Pemerintah Kota Kota Tasikmalaya memang belum memiliki Peraturan Daerah yang jelas dan hukum yang jelas untuk menurunkan angka stunting. Adapun di setiap programnya hanya mengatas namakan perbaikan gizi sedangkan untuk permasalahan gizi ini ada beberapa jenis yaitu overweight, wasted dan gizi buruk. Namun untuk tahun 2021 nanti akan ada konvergensi stunting di Kota Tasikmalaya, di tahun 2020 ini sudah memiliki Surat Keterangan yang telah disepakati dan disahkan oleh Walikota Tasikmalaya.

Kekurangan pada dimensi penegakan hukum ada pada Walikota Tasikmalaya yang memiliki komitmen rendah dan dinilai kurang tegas serta kurang memberikan perhatian khusus kepada permasalahan stunting meskipun angka stunting tergolong kecil di Kota Tasikmalaya namun peneliti berpendapat bahwa besar kecilnya angka stunting sangat perlu diprioritaskan penanggulangannya karena jika tidak maka akan berpengaruh ke depannya bagi pembangunan bangsa.

\subsection{Keberlanjutan Usaha}

Dalam dimensi Keberlanjutan Usaha memiliki arti sebuah usaha apakah dinilai baik atau lemah dan goyah. Bagaimana keberlanjutan kebijakan tersebut apakah terlaksana atau hanya sampai pada inisiatif saja sehingga sulit untuk mengharapkan keberlanjutannya. Jadi suatu inisiatif yang baik harusnya memikirkan bagaimana nasib kedepannya apakah jangka pendek atau untuk dampak masa panjang. Jika kebijakan berjangka panjang maka memungkinkan untuk terciptanya strategi baru serta target baru.

Niat dan Inisiatif Walikota Budi Budiman tercantum dalam RPJMD 20172022, artinya ada kebijakan Walikota dalam RPJMD yang berlaku selama masa periode pemerintahannya berakhir. Ketika masa pemerintahannya berakhir memungkinkan ada kebijakan baru, strategi serta tujuan baru. Namun di tahun 2021 nanti akan ada konvergensi stunting bersama Pemerintah Pusat.

Untuk mempertahankan kebijakan tersebut selama lima tahun maka dari Walikota, DPRD Komisi IV, Dinas Kesehatan dan OPD terkait ikut serta dalam 
rapat koordinasi yang diadakan selama satu bulan sekali. Dalam rapat tersebut diagendakan pengkajian bersama terkait apa yang menjadi kendala dan apa yang menjadi kasuistik. Namun dari Dinas Kesehatan punya cara tersendiri untuk mempertahankan kebijakan Walikota yaitu dengan terus melakukan penyuluhan selama lima tahun karena masyarakat Kota Tasikmalaya memiliki keterbatasan pengetahuan dan sumber daya manusia. Jadi dari kegiatan penyuluhan ini diharapkan mampu menanamkan pengetahuan dasar bagi masyarakat akan pentingnya status gizi dan bahayanya gizi buruk. Selain penyuluhan dilakukan pula kegiatan konseling gratis yang dibantu oleh pihak swasta yaitu RSUD dr. Soekardjo.

RSUD dr. Soekardjo memberikan dukungannya dengan berupaya mensosialisasikan cara mencegah stunting untuk masyarakat dengan penyuluhan kelompok yang dilakukan di depan klinik Obgyn dan klinik anak sesuai dengan targetnya yaitu ibu hamil, ibu menyusui, anak serta seluruh orang tua yang memiliki atau belum memiliki anak agar mereka lebih bisa sadar gizi sehingga stunting bisa dicegah sejak dini. Kegiatan lain pun dilakukan yaitu konseling secara gratis bagi seluruh pasien, keluarga pasien dan pengunjung rumah sakit bahkan terbuka juga untuk umum (dalam https://rsud.tasikmalayakota.go.id ). Selain itu dari Dinas Kesehatan mengupayakan kerjasama dengan Seksi Promosi Kesehatan untuk mempromosikan program-program gizi dengan memanfaatkan media sosial maupun surat kabar, banner, dan pamflet. Hal ini dilakukan guna lebih menekankan pada kegiatan promotif sebagai dasar dari pelaksanaan kegiatan gizi.

Kebijakan ini sudah berjalan selama empat tahun tentu memiliki strategi yang berbeda, dengan adanya program-program baru seperti Program Isi Piringku yang baru dilaksanakan di tahun 2020 di Kota Tasik. Program ini berupa penyuluhan secara langsung kepada masyarakat untuk mendorong masyarakat agar bisa mengisi piring dengan makanan yang bergizi, namun program ini tidak diperuntukan bagi balita dibawah usia satu tahun karena memerlukan gizi lebih untuk makanannya.

Masa pandemi bukan menjadi halangan bagi Dinas Kesehatan untuk terus mempertahankan keberlanjutan usaha agar kesehatan masyarakat tidak terabaikan. Selama masa ini Dinkes bersama Pemerintah Kota selalu melakukan koordinasi via daring menggunakan Zoom dan Whatsapp. Upaya lain pun dilakukan bersama para kader, petugas puskesmas dan staff Dinas Kesehatan dalam kegiatan penyuluhan dan open access terhadap pelayanan konsultasi daring utamanya bagi ibu hamil, dan ibu menyusui. Dinas Kesehatan pun mempermudah bagi masyarakat yang tidak bisa melakukan konsultasi via online dengan diberlakukannya pelayanan secara langsung yang masih dibatasi dan menyesuaikan protokol kesehatan.

Selain itu berdasarkan ungkapan warga di salah satu kecamatan di Kota Tasikmalaya bahwa selama masa pandemi ini tenaga kesehatan puskesmas masih aktif memberikan obat tambah darah bagi remaja putri dengan dikoordinasikan oleh salah satu kader bersama perwakilan remaja putri lalu tablet tambah darah tersebut diberikan kepada teman-temannya. Untuk membuktikan berjalannya kegiatan tersebut maka remaja putri yang menerima tablet tambah darah diharuskan untuk mendokumentasikan atau memfoto dirinya sendiri yang sudah meminum obat tersebut, dokumentasi yang telah 
disimpan dikirimkan pada tenaga kesehatan puskesmas sebagai tanda bukti untuk diserahkan kepada Dinas Kesehatan. Dari Dinas kesehatan itu sendiri memberikan tiga pilihan kepada remaja putri apakah mereka mau menerima obat yang diberikan oleh kader,datang langsung ke Dinas Kesehatan maupun puskesmas, atau membeli obat tambah darah sendiri secara mandiri, jika dilakukan secara mandiri Dinas Kesehatan tidak memberikan biaya kepada remaja putri untuk membeli obat tambah darah.

Berkenaan dengan hasil penelitian dalam dimensi keberlanjutan usaha, maka mampu ditarik simpulan bahwa dalam dimensi ini dinilai kurang karena keberlanjutan usaha hanya sampai pada berakhirnya periode Budi Budiman saja. Tidak ada arahan maupun dorongan lain untuk mempertahankan program ini khususnya Program Tasik Sehat akan berlanjut pada pemerintahan baru nanti. Adapun kekurangan dalam mempertahankan kebijakan tersebut ada pada masing-masing unit pelaksanannya kurang memiliki koordinasi seperti Dinas Kesehatan sebagai penanggung jawab utama tidak terlihat berkoordinasi dengan dinas lain seperti Dinas Pengendalian Penduduk, Keluarga Berencana, Pemberdayaan Perempuan dan Perlindungan Anak, dan Walikota pun kurang mendorong masing-masing OPD untuk bisa bekerja di bawah bendera yang sama karena inisiatif Walikota memiliki tujuan bernilai positif untuk kesejahteraan masyarakat dan pembangunan Kota Tasikmalaya. Maka perlu lebih ditekankan lagi serta didorong agar program-program pemerintah kota bisa berjalan dengan maksimal. Lalu Dinas Kesehatan yang kurang tegas dan kurang pengawasan terkait pemberian obat kepada remaja putri karena berdasarkan temuan di lapangan bahwa ada remaja putri yang tidak mengkonsumsi obat tambah darah melainkan hanya disimpan atau dibuang. Selain itu aksi dokumentasi hanya formalitas semata bukan sebagai bukti. Namun sejauh ini yang paling berperan besar adalah Dinas Kesehatan, dibuktikan dengan program kegiatannya yang banyak dan melibatkan banyak aktor di lapangan, Dinas Kesehatan pun tidak pernah lepas berkoordinasi dengan Walikota untuk perkembangan status gizi masyarakat Kota Tasikmalaya dan sebaliknya Walikota pun turut menekankan agar stunting bisa sampai zero stunting. Di samping masa pemerintahannya berakhir Kota Tasikmalaya hanya berpegang pada kebijakan pusat yaitu konvergensi stunting, selama ada program tersebut Dinas Kesehatan bertekad mampu mewujudkan harapan Walikota Budi Budiman untuk menurunkan stunting sampai nol.

\section{PENUTUP}

Bersandarkan pada hasil penelitian di atas maka peneliti menarik simpulan bahwa berhasilnya sebuah kebijakan atau program dinilai dari baiknya komitmen politik seorang pemimpin maupun pemerintahnya itu sendiri. Dibalik suksesnya Pemerintah Kota Tasik menurunkan angka stunting dalam waktu cepat masih terdapat nilai kurang dalam proses pelaksanaannya. Seperti aspek penegakan hukum yang dijabarkan di atas bahwa Pemerintah Kota Tasik ini belum memiliki hukum jelas terkait penurunan stunting. Meski begitu program-program tetap berjalan sebagaimana mestinya karena upaya dan usaha dari para unit pelaksana utamanya adalah Dinas Kesehatan hingga hasilnya angka stunting ini berhasil ditekankan di tahun 2019 mencapai 5,986 anak.

Hingga saat ini Pemerintah Kota Tasikmalaya mengejar target zero stunting yang mana akan sangat sulit jika dalam inisiatifnya saja hanya ada program- 
program perbaikan gizi, bukan program yang secara khusus mengatur permasalahan stunting. Kendati demikian di tahun 2021 nanti Pemerintah Kota Tasik bersinergi bersama Pemerintah Pusat dalam konvergensi stunting karena di tahun 2021 Kota Tasikmalaya sudah dalam kota yang diprioritaskan penurunan stuntingnya. Sehingga dikatakan untuk keberlanjutan usaha ke depanya dinilai positif mampu menurunkan stunting sampai nol.

Berdasarkan simpulan di atas peneliti memiliki rekomendasi ke depannya dalam aksi menurunkan prevalensi stunting yaitu:

1. Dimensi Penegakan Hukum peneliti memiliki penilaian bahwa Walikota Tasikmalaya kurang niat dalam menurunkan angka stunting maka diperlukannya penguatan dan pemberian sanksi tegas untuk programprogram perbaikan gizi. Selain itu peneliti mengharapkan adanya insentif yang jelas dapat berupa pemberian hal-hal yang bermanfaat bagi unit pelaksana seperti pemberian laptop atau alat penunjang bagi mereka dalam melaksanakan program kegiatan. Maka dengan adanya hal tersebut diharapkan bisa mendorong semangat bekerja dari para unit pelaksana agar bisa mencapai zero stunting di tahun 2020 ini. Lalu untuk wilayah kecamatan di Kota Tasikmalaya yang berhasil menurunkan angka stunting tercepat maka harus diberi insentif berupa penghargaan maupun pemberian sarana dan prasarana penunjang pola hidup sehat. Seperti disediakannya tempat untuk konseling atau konsultasi dengan suasana yang mendukung dan memberikan rasa nyaman khususnya pada ibu hamil karena ibu hamil memerlukan perhatian lebih agar bisa melahirkan anak dalam kondisi yang sehat.

2. Berkenaan dengan aspek keberlanjutan usaha dikatakan memang sudah banyak aksi dalam perbaikan gizi, namun dalam aksi tersebut alangkah baiknya jika berlangsung sampai pada pemerintahan baru nanti meskipun di tahun 2021 akan ada konvergensi stunting memungkinkan bagi Walikota untuk terus mendorong program-program yang ada terkait masalah gizi agar senantiasa saat konvergensi stunting nanti pemerintah bisa dengan cepat mencapai zero stunting. Selain keberlanjutan usaha, untuk mempertahankannya diperlukan dorongan dari Walikota terhadap unit pelaksana utamanya adalah OPD terkait agar senantiasa bisa berkoordinasi bersama menanggulangi masalah stunting. Jika memiliki koordinasi baik dan dorongan dari Walikota penulis yakin dengan kondisi yang sekarang 10,95\% anak stunting maka di tahun 2021 nanti pada saat konvergensi Pemerintah Kota Tasikmalaya bisa mencapai zero stunting dalam waktu dekat.

\section{DAFTAR PUSTAKA}

Badan Pusat Statistik Kota Tasikmalaya. (2020). Statistik Daerah Kota Tasikmalaya $2020 \quad$ (Vol. 20 53, Issue 9). https://doi.org/10.1017/CBO9781107415324.004

Boli, E. B., Baliwati, Y. F., \& Sukandar, D. (2018). Komitmen Politik dan Peluang Pengembangan Kebijakan Gizi Pemerintah Daerah Provinsi Nusa Tenggara Timur. Media Kesehatan Masyarakat Indonesia, 14(4), 351. https: / / doi.org/ 10.30597/mkmi.v14i4.5104

Brinkerhoff, D. W. (2010). Unpacking the concept of political will to confront corruption. U4BRIEF Anti- Corruption Resource Centre, 1, 2-3. 
Chopra, D. (2015). Political commitment in India's social policy implementation: Shaping the performance of MGNREGA (Issue 50). https://doi.org/https://doi.org/10.1163/2210-7975_hrd-0148-2015081

Dolf, J. H., Page, P., Kaganda, J., \& Esau, D. (2020). Tanzania' s story of change in nutrition: Political commitment, innovation and shrinking political space. Global Food Security, 24(January), 100350. https://doi.org/10.1016/j.gfs.2020.100350

Fauzy, A. (2015). POLITICAL WILL PEMERINTAH KABUPATEN PELALAWAN TERHADAP PELESTARIAN SATWA DI TAMAN NASIONAL TESSO NILO TAHUN 2011-2012. JOM FISIP, 2(2), 4-9.

Ishartono, R. S. . (2016). SUSTAINABLE DEVELOPMENT GOALS (SDGs) DAN PENGENTASAN KEMISKINAN. SHARE: SOCIAL WORK JURNAL, 6(2), 159160. https://doi.org/10.5005/jp/books/13071_5

Janoušková, S., Hák, T., \& Moldan, B. (2018). Global SDGs assessments: Helping or confusing indicators? Sustainability (Switzerland), 10(5), 2. https://doi.org/10.3390/su10051540

Kementerian Kesehatan Republik Indonesia. (2018). Buletin Stunting. In Buletin Jendela Data dan Informasi Kesehatan (Vol. 301, Issue 5, p. 2). https://doi.org/https://doi.org/10.1017/CBO9781107415324.004

Kementerian PPN/ Bappenas. (2018). Pedoman Pelaksanaan Intervensi Penurunan Stunting Terintegrasi di Kabupaten/Kota. Rencana Aksi Nasional Dalam Rangka Penurunan Stunting: Rembuk Stunting, November, 151. https://www.bappenas.go.id

Lestari, W., Kristiana, L., \& Paramita, A. (2018). Stunting: Studi Konstruksi Sosial Masyarakat Perdesaan dan Perkotaan Terkait Gizi dan Pola Pengasuhan Balita di Kabupaten Jember. Jurnal Aspirasi, 9(1), 17-33. https://doi.org/10.22212/aspirasi.v9i1.985

Liverman, D. M. (2018). Geographic perspectives on development goals: Constructive engagements and critical perspectives on the MDGs and the SDGs. Dialogues in Human Geography, 8(2), 169-177. https: / / doi.org/10.1177/2043820618780787

Nur, I. T. (2014). MEMANTAPKAN LANDASAN HUKUM FORMIL SEBAGAI ALAT SINGKRONISASI DAN HARMONISASI PERATURAN PERUNDANG UNDANGAN. YURISKA: JURNAL ILMIAH HUKUM, 1O(2), 160. https://doi.org/https://doi.org/10.24903/yrs.v10i2.355

Pastuty, R., KM, R., Herawati, T. (2018). EFEKTIFITAS PROGRAM PEMBERIAN MAKANAN TAMBAHAN- PEMULIHAN PADA IBU HAMIL KURANG ENERGI KRONIK DI KOTA PALEMBANG. Jurnal Ilmu Kesehatan Masyarakat, 9 (3)(November), 184. doi: https://doi.org/10.26553/jikm.2018.9.3.179-188

Putri, R. F., Sulastri, D., \& Lestari, Y. (2015). Faktor-Faktor yang Berhubungan dengan Status Gizi Anak Balita di Wilayah Kerja Puskesmas Nanggalo Padang. Jurnal Kesehatan Andalas, 4(1), 255. https://doi.org/10.25077/jka.v4i1.231

R. Saputri, J. T. (2019). HULU-HILIR PENANGGULANGAN STUNTING DI INDONESIA. JPI: Jurnal of Political Issues, 1(1), 1-9. https://doi.org/https://doi.org/10.33019/jpi.v1i1.2

Rahayu, D. T., \& Sagita, Y. D. (2019). POLA MAKAN DAN PENDAPATAN KELUARGA DENGAN KEJADIAN KEKURANGAN ENERGI KRONIK (KEK) PADA IBU HAMIL TRIMESTER II. Holistik Jurnal Kesehatan, 13(1), 15. 
https://doi.org/https://doi.org/10.33024/hjk.v13i1.847

Rassanjani, S. (2018). Indonesian Housing Policy and Sustainable Development Goals (SDGs). Otoritas: Jurnal Ilmu Pemerintahan, 8(1), 45. https://doi.org/10.26618/ojip.v8i1.760

Sarabhai, K. V. (2015). ESD for Sustainable Development Goals (SDGs). Journal of Education for Sustainable Development, 9(2), 121-123. https://doi.org/10.1177/0973408215600601

Wahyuningsih. (2018). Millenium Develompent Goals (Mdgs) Dan Sustainable Development Goals (Sdgs) Dalam Kesejahteraan Sosial. Bisma, 11(3), 391. https: / / doi.org/10.19184/ bisma.v11i3.6479

World Health Organization. (2013). Global nutrition policy review: (p. 11). https://apps.who.int/iris/rest/bitstreams/300168/retrieve

Peraturan Pemerintah:

Undang-Undang Nomor 22 Tahun 2003 tentang Susunan dan Kedudukan MPR/DPR/DPRD/DPD

Undang-Undang Nomor 32 Tahun 2004 tentang Pemerintahan Desa

Pemerintah Kota Tasikmalaya. (2019). Laporan Penyelenggaraan Pemerintahan Daerah 2019.

Pemerintah Kota Tasikmalaya. (2018). Rencana Pembangunan Jangka Menengah Daerah 2017-2022.

Pemerintah Kota Tasikmalaya. (2019). Rencana Kerja Pemerintah Daerah Kota Tasikmalaya 2020. 